\title{
Nicht invasive Pränataldiagnostik als Ergånzung der pränatalen Sonografie
}

In der wissenschaftlichen Literatur, gefolgt von den Medien, ist die nicht invasive Pränataldiagnostik (NIPD) derzeit ein großes Thema. Seit mehr als 2 Dekaden wird daran geforscht, aus mütterlichem Blut fetale genetische Merkmale zu identifizieren. Während dies in den letzten Jahren in Einzelfällen, beispielsweise bei der Bestimmung des fetalen Rhesusfaktors gelungen ist, war dies für die fetale Trisomiediagnostik nicht möglich. Erst die Abkehr vom Prinzip der Isolierung fetaler Zellen hin zum Sammeln und Konzentrieren fetaler DNA hat diesbezüglich den Durchbruch gebracht.

Die in Kürze zur Verfügung stehende nicht invasive Diagnostik für Trisomie 21, noch unzuverlässiger für Trisomie 18 und 13, wird die Arbeit der PränatalmedizinerInnen verändern. Die Detektionsraten für die genannten Trisomien werden mit 98\% bis über 99\% angegeben. Dennoch wird der Test nicht als diagnostischer Test, sondern als sekundärer Screening-Test gesehen. Die jetzigen vorliegenden Daten, die solch hohe Erkennungsraten zeigen, sind in Risikokollektiven erstellt. Ob diese Erkennungsraten auch im Low-Risk-Kollektiv zu erreichen sind, müssen erst weitere Studien zeigen. Ein breiter Einsatz als primäres Screening-Instrument wird in Österreich zumindest in naher Zukunft der 4-stellige Europreis verhindern. Das jetzige Szenario sieht eher vor, bei auffälligem primärem Screening durch Ultraschall und evtl. Biochemie ihn als Zwischenstufe zwischen dem auffälligem primären Screening-Test und der Chorionbiopsie oder Amniozentese einzusetzen. Die Herausforderung für die Pränatalmediziner und Genetiker wird sein, der Schwangeren bzw. dem Paar die Aussagekraft der NIPD ausreichend nahe zu bringen. Argumentiert wird, dass mit der Anwendung des Testes damit die Zahl der Punktionen und damit auch die Zahl der gesunden eingriffsbedingten fetalen Verluste reduziert werden kann. Dies ist allerdings nur dann möglich, wenn die Schwangere das Restrisiko eines allfälligen falsch negativen Testergebnisses trägt. Das klinische Problem und das forensische Risiko ist damit skizziert.

Eine Reihe von österreichischen PränatalexpertInnen hat dieses Thema gemeinsam diskutiert. Frau Prof. Pertl hat eine diesbezügliche Stellungnahme zusammengefasst, welche auf der Homepage abrufbar ist. Gerade zum Redaktionsschluß hat die in Deutschland und Österreich kooperierende Firma aufgrund legistischer Bedenken die im Juli geplante Einführung des Testes zurückgestellt. Wie es diesbzüglich weitergeht, kann derzeit nicht abgeschätzt werden. Jedenfalls wird mit der NIPD dem Ultraschall ein weiteres Diagnostikum zur Seite gestellt, welches unser sonografisches Tun ergänzt, keinesfalls aber ersetzt. 